\title{
Research On Subjective Response To Simulated Sonic Booms At NASA Langley Research Center
}

\author{
Brenda M. Sullivan \\ NASA Langley Research Center, Hampton, Virginia, 23681
}

\begin{abstract}
Over the past 15 years, NASA Langley Research Center has conducted many tests investigating subjective response to simulated sonic booms. Most tests have used the Sonic Boom Booth, an airtight concrete booth fitted with loudspeakers that play synthesized sonic booms pre-processed to compensate for the response of the booth/loudspeaker system. Tests using the Booth have included investigations of shaped booms, booms with simulated ground reflections, recorded booms, outdoor and indoor booms, booms with differing loudness for bow and tail shocks, and comparisons of aircraft flyover recordings with sonic booms. Another study used loudspeakers placed inside people's houses, so that they could experience the booms while in their own homes. This study investigated the reactions of people to different numbers of booms heard within a 24-hour period. The most recent Booth test used predicted boom shapes from candidate low-boom aircraft. At present, a test to compare the Booth with boom simulators constructed by Gulfstream Aerospace Corporation and Lockheed Martin Aeronautics Company is underway. The Lockheed simulator is an airtight booth similar to the Langley booth; the Gulfstream booth uses a traveling wave method to create the booms. Comparison of "realism" as well as loudness and other descriptors is to be studied.
\end{abstract}

Keywords: Sonic boom, human response, simulation.

PACS: 43.66

\section{INTRODUCTION}

NASA's High Speed Research (HSR) program in the 1990s was intended to develop a technology base for a future 300-passenger High-Speed Civil Transport (HSCT). As part of this program, the NASA Langley Research Center sonic boom simulator (SBS) was built and used for a series of tests on subjective response to sonic booms. At the end of the HSR program, an HSCT was deemed impractical, but since then interest in supersonic flight has reawakened, this time focusing on a smaller aircraft. The demonstrated ability to design a "low-boom" aircraft has encouraged reappraisal of the FAA ruling that supersonic flight should be banned overland, because of the impact of sonic boom on the community.

This paper presents an overview of work of human response to sonic boom completed at NASA in the 1990s, and a summary of studies performed since then on the impact of low-intensity sonic booms, including work performed as part of Project 8 of the FAA/NASA/Transport Canada Center of Excellence Partnership for Air Transportation Noise and Emissions Reduction (PARTNER). Details of PARTNER can be found at http://web.mit.edu/aeroastro/www/partner/mission.htm. 


\section{RESPONSE TO SONIC BOOM 1990-1996}

During the 1990s, NASA Langley Research Center conducted three groups of studies on sonic booms: laboratory, "inhome" and field. These three complementary parts consisted of (a) laboratory studies, which have very good control over the sound stimuli that the subjects hear but require a very abnormal listening environment; (b) an "inhome" study where sounds are played through loudspeakers in people's homes, thus improving the realism of the environment but reducing the control over the sound field; and (c) field studies with completely normal environment but very poor knowledge of the precise details of the sound exposure. The "acceptability" of or "annoyance" caused by a sound is affected by many factors. In a laboratory situation, while some of these factors are under control, others may be missing. Thus ratings of sounds can be considered as accurate relative to one another, but not in an absolute sense. The inhome study moves closer to absolute measurements and the field studies measure absolute, real reactions. A compilation of these studies, with details of the findings, is given in Leatherwood et al. [1].

\section{Laboratory Studies}

The laboratory experiments were designed to (a) develop an improved understanding of sonic boom subjective effects; (b) quantify in a systematic and comprehensive manner the loudness and annoyance benefits due to intentional sonic boom shaping as well as distortions due to passage through walls, ground reflections, and atmospheric propagation; and (c) assess various noise descriptors as predictors of sonic boom subjective effects. To study these factors, NASA Langley built a Sonic Boom Simulator (SBS). Construction details, performance capabilities, and operating procedures of the simulator were described by Leatherwood et al. [2]. The simulator is a person-rated, airtight, loudspeaker driven booth, carpeted and lined with foam to reduce acoustic resonances, and free of loose objects capable of creating rattles. Input waveforms are computer generated and preprocessed to compensate for non-uniformities in the magnitude and phase characteristics of the frequency response of the booth and sound reproduction system. Preprocessing is accomplished by the use of a digital broadband equalization filter as described by Brown and Sullivan [3]. One significant finding from the series of 14 studies conducted in the SBS were that subjective reactions to simulated sonic booms were predicted well by calculated loudness metrics, such as Steven's Perceived Level (PL). The metric and its application to sonic boom are described in Shepherd and Sullivan [4]. Such metrics as unweighted or $\mathrm{C}$-weighted $\mathrm{dB}$ or peak overpressure were poor predictors of human response.

\section{Inhome Study}

One question affecting assessment of a sound exposure is the combination of single events into a long-term multiple-event situation. Within the laboratory, such combining of reactions is unrepresentative of a realistic situation. To enable the investigation of more realistic multiple-event environments, Langley Research Center 
completed an "inhome" study (McCurdy et al. [5]) in which simulated sonic booms were played through loudspeaker systems in people's homes. Various scenarios involving different numbers of booms at different levels were played, with participants giving annoyance judgments after a day's exposure. The study confirmed that the increase in annoyance resulting from multiple occurrences can be modeled by the addition of the term " $10 \times(\log ($ Number of Occurrences $)$ " to the sonic boom level.

\section{Field Studies}

The third part of NASA Langley Research Center's program to study subjective response to sonic boom was a series of field studies in which the responses of community residents experiencing supersonic overflights were measured, together with their boom exposures. This study was unique in that no other study has investigated the reactions of people routinely exposed to sonic booms over a long time period. As reported in Fields [6], the study found that sonic boom annoyance increased as the number and/or level of the booms increased. Large differences noted in responses from two localities were not attributable to sonic boom exposure, but were explained in part by differences in attitudes towards the "noise makers" and differences in exposure to low altitude, subsonic aircraft flyovers.

\section{RESPONSE TO LOW-INTENSITY SONIC BOOM}

Recent interest in "low-boom" aircraft prompted NASA Langley Research Center to complete a study in 2003 (Sullivan [7]) that used twenty-four predicted lowintensity boom waveforms resulting from designs of candidate aircraft supplied by aircraft designers. Participants rated these sounds presented in the SBS at the levels expected for the aircraft operating under cruise conditions. As was expected, unweighted and C-weighted Sound Exposure Levels, and overpressure were not good predictors of human response as measured in the SBS; PL and A-weighted Sound Exposure Level were good predictors. These metrics predicted the loudness of complex, multishocked booms and simple booms equally well.

\section{SIMULATOR ASSESSMENT}

As part of Project 8 of the Partnership for AiR Transportation Noise and Emissions Reduction (PARTNER) (a FAA/NASA/Transport Canada-Sponsored Center of Excellence) an evaluation of three sonic boom simulators to determine if they can reproduce realistic sonic booms is under way. This consists of a series of three experiments at NASA Langley, NASA Dryden and Lockheed Martin's Palmdale facility in California. The Lockheed Martin simulator is a very similar design to the SBS, both being airtight booths that achieve the characteristic sonic boom N-wave shape by compressing the air within the booth. The Gulfstream simulator (Salamone [8]) is a folded-horn design which creates a pressure wave that travels past the listener into an anechoic termination. This "traveling wave" simulation is closer to the pressure waveform of a real sonic boom than the booths' compression simulation. 
However the Gulfstream simulator cannot recreate the very low frequencies (below $7 \mathrm{~Hz}$ ) that are present in a sonic boom, but which can be created in the Langley simulator.

In the first test, participants experienced in listening to sonic booms evaluated the realism of booms played in the NASA and the Gulfstream simulators. In the second test subjects heard supersonic military jet flyovers and afterwards rated the realism of recordings of some of those flyovers reproduced in the Gulfstream simulator. In the third test in this realism series, expert listeners will evaluate the Lockheed Martin and the Gulfstream simulators.

In the NASA/Gulfstream back-to-back comparison test, the sounds used were all created from recordings of F-18s and F-5Es made during the Shaped Sonic Boom Experiment at Edwards AFB in January 2004. In order to identify important characteristics of sonic boom sounds, some booms were modified in various ways, including (1) high pass filtering to remove the low frequencies so the booms in the NASA LaRC simulator would have the same frequency content as those in the Gulfstream simulator; (2) the addition of a synthesized "ground reflection" to simulate what a listener standing above hard ground would hear; (3) modification of the length of the recording to vary the amount of noise that was heard after the boom. Preliminary results indicate that the absence of the very low frequencies was less important in the sensation of realism than the "feeling" imparted by the traveling wave. Also evident is the importance of the "post-boom" noise in giving an impression of realism to the simulations. This post-boom noise is not fully understood, but is considered to be a combination of engine noise and boom sounds that have been disturbed by turbulence and have traveled by complex paths through the atmosphere to reach the listener after the direct boom.

\section{REFERENCES}

1. Leatherwood, J. D., Sullivan, B. M., Shepherd, K. P., McCurdy, D. A., and Brown, S. A., "A summary of recent NASA studies of human response to sonic booms", J. Acoust. Soc. Am., 111(1) pt. 2, 586-598 (2002).

2. Leatherwood, J. D., Shepherd, K. P., and Sullivan, B. M., "A New Simulator for Assessing Subjective Effects of Sonic Booms", NASA Tech. Memo. 104150, 1-35 (1991) http://ntrs.nasa.gov/archive/nasa/casi.ntrs.nasa.gov/19920002541 1992002541.pdf.

3. Brown, D. E., and Sullivan, B. M., "Adaptive Equalization of the Acoustic Response in the NASA Langley Sonic Boom Chamber" Proceedings, International Conference on Recent Advances in Active Control of Sound and Vibration, VPI \& SU, Blacksburg, Virginia, 360-371 (1991)

4. Shepherd, K. P., and Sullivan, B. M., "A Loudness Calculation Procedure applied to Shaped Sonic Booms", NASA Technical Paper 3134, 1-10 (1991) http://hdl.handle.net/2002/14923

5. McCurdy, D. A., Brown, S. A., and Hilliard, R. D., "Subjective Response of People to Simulated Sonic Booms in their Homes" J. Acoust. Soc. Am. 116(3) 1573-1584 (2004)

6. Fields, J. A.: "Reactions of Residents to Long-Term Sonic Boom Noise Environments" NASA Contractor Report 201704, 1-157 (1997) http://ntrs.nasa.gov/archive/nasa/casi.ntrs.nasa.gov/19970023685 1997038340.pdf

7. Sullivan, B. M., "Human Response to Simulated Low-Intensity Sonic Booms" Proceedings of NOISE-CON 2004, Baltimore, Maryland, 541-550 (2004) http://techreports.larc.nasa.gov//trs/PDF/2004/mtg/NASA-2004-noisecon-bms.pdf

8. Salamone, J., "Portable Sonic Boom Simulation" Proceedings of the $17^{\text {th }}$ International Symposium on Nonlinear Acoustics, American Institute of Physics Press (2005) 